\title{
Exploring practising pharmacy graduates' views on improving the effectiveness of pharmacy education at the University of the Western Cape, South Africa
}

M van Huyssteen, $\mathrm{PhD}, \mathrm{MSc}, \mathrm{BPharm}$; A Bheekie, $\mathrm{PhD}$, MPharm, BPharm, BSc

School of Pharmacy, Faculty of Natural Science, University of the Western Cape, Cape Town South Africa

Corresponding author: $M$ van Huyssteen (mvanhuyssteen@uwc.ac.za)

\begin{abstract}
Background. South African health professional education institutions have a mandate to produce graduates who are able to address priority needs of the healthcare system and larger society. However, evidence of the effective use of public resources by health education institutions is not routinely collected. Practising graduates are a target audience who could provide part of this evidence.

Objectives. To explore the views of University of the Western Cape (UWC) pharmacy graduates on the effectiveness of pharmacy education in relation to their current and anticipated practice aspirations.

Methods. A cross-sectional electronic survey was administered to UWC pharmacy graduates through the university's alumni office network.

Results. Twenty-five graduates responded, of whom 60\% were male (average age 38.9 (standard deviation 9.52) years). One of the strongest themes that emerged was the need for exposing pharmacy students from early on in the curriculum to a broad range of pharmacy and healthcare sectors and addressing real issues in these changing and complex environments. Graduates stressed the importance of the development of generic skills, such as interpersonal skills, leadership, advocacy and innovative problem-solving, which are necessary to effect positive change through collaborative and equitable approaches.

Conclusions. The findings are aligned with general trends in health education reform, such as embedding undergraduate training in the healthcare system and development of generic skills. Routine and reciprocal communication with graduates might be a valuable resource to monitor and evaluate educational outcomes to strengthen the healthcare system and benefit society.
\end{abstract}

Afr J Health Professions Educ 2019;11(3):77-80. https://doi.org/10.7196/AJHPE.2019.v11i3.1065

Higher education is increasingly seen as a major engine of economic development, thus implying that there is a need to produce graduates who are able to effectively further the public good. ${ }^{[1]}$ This echoes the sentiments of broader health education reform, whereby a co-ordinated effort between health education and the local healthcare system is required to pool resources towards the realisation of universal health coverage. ${ }^{[2]}$ This would mean that educational outcomes should be systematically tracked to identify indicators that have the greatest impact on society, i.e. return on investment. ${ }^{[1]}$

However, measuring the effectiveness of health education has been limited by historical isolation between health education institutions and health service delivery platforms. ${ }^{[3]}$ Furthermore, accreditation requirements of professional councils generally consider evidence of the impact of graduates on the community and on practice outside the scope of educational institutions. ${ }^{[4]}$ A global systematic review of the impact of health professional education showed a general paucity of evidence to support the effectiveness of current educational approaches at a societal level. ${ }^{[5]}$ A key question is: how can health education institutions focus their activities to ensure maximal effectiveness of their educational programmes? A target audience that is often overlooked is practising graduates, whose experience and insight could be useful in monitoring and evaluating educational outcomes to strengthen the healthcare system and benefit society.

The purpose of this study was to explore the views of pharmacy graduates of the University of the Western Cape (UWC) on the effectiveness of pharmacy education in relation to their current and anticipated practice aspirations. The results of this article form the baseline/pilot for a larger longitudinal study on establishing a partnership between the School of Pharmacy, UWC, and its graduates to create a continuous dialogue regarding the relevance of the pharmacy curriculum to prepare graduates to address the needs of society, thereby illustrating educational effectiveness.

\section{Methods}

This was a cross-sectional exploratory study. An electronic survey was administered to graduates at the School of Pharmacy, UWC, through the network of the university's alumni office. The survey used a structured questionnaire containing closed and open-ended questions to elicit practising pharmacy graduates' opinions.

The target population included practising pharmacists who graduated from UWC and who were involved in the School's experiential learning programme as a student or a practising pharmacist. Exclusion criteria included graduates not from UWC, those who were not practising pharmacists, and those who did not take part in the experiential learning programme as a student or as a practising pharmacist.

By means of the alumni office database we made contact with UWC pharmacy graduates by email. They were invited to participate in the study by downloading a link to the questionnaire. The first section of the electronic survey contained the information sheet and a space for 
participants to indicate their informed consent. As a means of snowball sampling, the invitation and link were also posted on the UWC Alumni Facebook page to further recruit graduates.

The 3-part questionnaire consisted of: (i) baseline demographics; (ii) details of the participants' current practice of pharmacy; and (iii) inquiry into their pharmacy education at UWC, which concluded with 3 open-ended questions:

- What advice do you have for pharmacy training institutions to make the training more relevant and beneficial for pharmacy practice in South Africa (SA)?

- How can practising pharmacists engage with pharmacy training institutions to improve the quality of graduates?

- When thinking about the future of pharmacy practice, could you recommend changes that would benefit the health system/larger society?

Quantitative data were analysed using descriptive statistics, and the 2 researchers independently coded and thematically analysed the 3 open-ended question responses.

\section{Ethical approval}

Ethical approval for the study was obtained from UWC's Senate Research Ethics Committee (ref. no. 15/6/101).

\section{Results}

On 23 May 2016, the questionnaire was first emailed to 398 pharmacy graduates; only 116 of the emails were opened. Thereafter, the alumni office updated its database and a second email was forwarded on 14 June 2016 to 744 pharmacy graduates, including the previous 398 cohort (as a reminder). Only 185 of these emails were opened. A third reminder was sent out to 744 graduates, of which 149 were opened. From the three attempts, only 25 graduates completed the survey. The average age of all the participants was 38.9 (standard deviation 9.52) years and most were male graduates $(60 \%)$. The current workplace of most respondents was in SA $(n=24 ; 96 \%)-44 \%$ were working in Western Cape Province (only 1 respondent worked outside Cape Town). Further details on demographics are given in Appendix A.

The thematic analysis is summarised in Table 1 . The three most prominent themes regarding graduates' advice for making the curriculum more relevant and beneficial to pharmacy practice related to explicitly linking pharmacy students and practitioners working in the SA healthcare system, expanding experiential learning for students and education opportunities for graduates. Most graduates $(n=14)$ suggested exposing students to a wider range of pharmacy and healthcare sectors during undergraduate education. They also suggested that this broader exposure needed to be combined with generic skills development, such as interpersonal skills, leadership, entrepreneurship, management and skills to promote public health. In conjunction with broader exposure to aspects of the healthcare system, one-third of graduates $(n=9)$ recommended more experiential learning from early on in the curriculum, with learning outcomes integrated across disciplines and different sectors of pharmacy. Another less-mentioned theme included postgraduate training relating to continuing professional development (CPD) $(n=5)$ and more specialised postgraduate short courses $(n=4)$.

Table 1. Thematic analysis of the 3 open questions put to respondents

1. What advice do you have for pharmacy training institutions to make pharmacy training more relevant and beneficial for pharmacy practice in South Africa?

Theme 1.1: Embedding of pharmacy education in the healthcare system

'I think institution staff should be directly involved at the practice level to gauge the role of pharmacists and how it's changing at the realistic level. In this

way changes can be incorporated immediately ... I think time is of the essence to adapt [teaching methods and materials] to changing needs and roles. ${ }^{\text {? }}$ ]

Theme 1.2: Expand experiential learning

'Expose students in the very early years of their studies to the various industries ... financial management studies or business/entrepreneurship would be beneficial. ${ }^{[9]}$

Theme 1.3: Education for graduates

'[university $\mathrm{x}$ ] has found its niche in developing the DPharm degree. I wish that UWC could do the same in making it more of a home for postgrad and alumni studies.'[2]

2. How can practising pharmacists engage with pharmacy training institutions to improve the quality of graduates?

Theme 2.1: Value of pharmacists' engagement in education

'For the different modules that are offered, if institutions could have a pharmacist from the different sectors of pharmacy coming and sharing their experiences with the learners ... and maybe try to see how the learners can resolve some of those issues if they were to come across them. Just to have that kind of interaction between an experienced pharmacist, old and young, with the learners.'[24]

Theme 2.2: Multisectoral engagement

'To obtain participation and valuable contribution [of graduates] it may be necessary to have regular interaction with pharmacists from different sectors representing different issues. In this way the real issues of various communities become known. This will give training institutions better insights on what needs to be changed and adapted. ${ }^{[8]}$

3. When thinking about the future of pharmacy practice, recommend changes that would benefit the health system or larger society

Theme 3.1: Generic skills

'Pharmacists need to take active roles in working and collaborating with other healthcare professionals ... Healthcare is moving towards electronic or digital processes, thereby implying that pharmacists need to start learning or adjusting to the changing environment.[19]

Theme 3.2: Equity (universal health coverage)

'They should lead quality improvement and multidisciplinary teams to strengthen health systems. They should be managing health systems strengthening programmes, which would entail more engagement with partners and at different levels of government ... I implore pharmacists to make a difference in rural, resource-limited settings! ${ }^{[3]}$ 
In response to the question on how the school and pharmacists could engage to increase the quality of graduates, there was general consensus that practising pharmacists had a valuable contribution to make in terms of student training. Some suggested increasing the number of faceto-face lectures and workshops between graduates and students, and electronic communication between the school and graduates. Multisectoral involvement was a common suggestion to strengthen these potential collaborative efforts and address issues.

Lastly, graduates' opinion of the future of the practice of pharmacy and efforts to advance the profession culminated in the emergence of a common underlying theme relating to the changing healthcare environment and the ability to seize service delivery opportunities borne from these challenges in the healthcare system. The most often-mentioned examples of changes that could improve quality in the profession and strengthen the healthcare system were towards embracing primary healthcare practice, addressing universal health coverage and innovation.

\section{Discussion}

This exploratory study attempted to start a dialogue with graduates to guide pharmacy education at UWC towards more effective educational outcomes in the healthcare system and larger society. This discussion focuses on two cross-cutting themes that repeatedly emerged from the 3 open questions posed to the 25 respondents, which centred around embedding the curriculum in the context of the larger healthcare system and focusing on the development of generic competencies of UWC pharmacy students to strengthen the healthcare system.

Based on the requests from the 25 graduates to include more sectors of pharmacy and health in education, it seemed clear that current pharmacy education at UWC is not well contextualised within the wider healthcare system. This stance is supported by the problem statement of the Lancet commission on health education reform that underscored the narrow technical focus of health education without having a broader contextual understanding of health. ${ }^{[2]}$ A pharmacy-graduate study conducted at another SA university noted low skills acquisition in subjects related to activities such as drug use, reviews and screening, ${ }^{[6]}$ which require engagement with the wider healthcare system beyond pharmaceutical services.

The call for the development of generic skills, which includes interpersonal skills, teamwork, advocacy, leadership and entrepreneurial skills, seemed to be important to all 25 respondents. This tendency has been noted in higher-education trends in resource-constrained countries, where there is often tension between producing specialists and technical professionals $\mathrm{v}$. strong leaders with generalist knowledge who are creative, adaptable and able to give broad ethical consideration to social advances. ${ }^{[1]}$ A comparative study from 4 developed countries, which mapped the learning outcomes for pharmacy graduates against the International Pharmaceutical Federation (FIP)'s global competency framework, found that the global framework was geared towards producing pharmacists who would be skilled primarily as medicine experts offering patient-centred care, but was lacking in its reference to generic competencies such as (interprofessional) teamwork and leadership attributes. ${ }^{[7]}$ Other generic orientations and skills, such as the ability to offer comprehensive primary healthcare services and undertaking advocacy work, have been discussed in wider health education circles. ${ }^{[4]}$ This underscores the constantly changing environment that graduates have to navigate as health needs and systems change over time.

\section{Study limitations}

Limitations of this study include the small sample size and graduate self-reporting. Similarly, other graduate-tracking studies have shown notoriously poor response rates - one of the primary challenges to electronic surveys. ${ }^{[8]}$

\section{Conclusions}

The findings of this study, however limited, aligned with general trends in health education, such as embedding education in the healthcare system and development of generic skills. Establishing a routine and reciprocal method of communication with UWC graduates is one way for the School of Pharmacy to offer evidence to gauge educational effectiveness. A longitudinal tracking approach might be more effective $e^{[4]}$ to secure meaningful engagement between graduates and their educational institution.

\section{Declaration. None.}

Acknowledgements. Pharmacy graduates who participated in the study and the fourth-year pharmacy research student group.

Author contributions. $\mathrm{MvH}$ and $\mathrm{AB}$ : conceptualised the research project; $\mathrm{MvH}$ : collected the data and performed the first analysis; $\mathrm{AB}$ : performed the second analysis; MvH: wrote the first draft; $\mathrm{AB}$ : edited the article.

Funding. National Research Foundation: Community Engagement Grant (2015 2017).

Conflicts of interest. None.

\footnotetext{
. Altbach PG, Reisberg L, Rumbly LE. Trends in Global Higher Education: Tracking an Academic Revolution. A Report Prepared for the UNESCO 2009 World Conference on Higher Education. Paris: United Nation Educational, Scientific and Cultural Organization, 2009.

2. Frenk J, Chen L, Bhutta ZA, et al. Health professionals for a new century: Transforming education to strengthen health systems in an interdependent world. Lancet 2010;376(9756):1923-1958. https://doi.org/10.1016/S01406736(10)61854-5

3. Boelen C, Woollard RF. Social accountability and accreditation: A new frontier for educational institutions. Med Educ 2009;43(9):887-894. https://doi.org/10.3109/0142159X.2011.590248

4. Larkins SL, Preston R, Matte MC, et al. Measuring social accountability in health professional education Development and international pilot testing of an evaluation framework. Med Teach 2013;35(1):32-45. https:// Development and international pilot test
doi.org/10.3109/0142159X.2012.731106

5. Reeve C, Woolley T, Ross SI, et al. The impact of socially-accountable health professional education: A systematic Reeve C, Woolley T, Ross SJ, et al. The impact of socially-accountable health professional
review of the literature. Med Teach 2017;39(1):67-73. https://doi.org/10.1080/0142159X

6. Naidoo P, Govender T, Hoosen T, et al. Identifying perceptions of the University of KwaZulu-Natal graduates on the relevance and adequacy of the pharmacy curriculum to current pharmacy practice. S Afr Pharmaceutical I 2009;76(10):36-43

7. Stupans I, Atkinson J, Mestrovic A, et al. A shared focus: Comparing the Australian, Canadian, United Kingdom and United States pharmacy learning outcome frameworks and the global competency framework. Pharmacy 2016;4(26). https://doi.org/10.3390/pharmacy4030026

8. Mijic D, Janovic D. Using ICT to support alumni data collection in higher education. Croatian J Educ 2014;16(4):1147-1172. https://doi.org/10.15516/cje.v16i4.613
} 


\section{Short Research Report}

\begin{tabular}{ll} 
Appendix A. Baseline demographics, pharmacy education and current \\
workplace details of respondents $(N=25)$ & \\
\hline Baseline demographics & $\boldsymbol{n}(\%)$ \\
\hline Gender & $25(100)$ \\
Female & $10(40)$ \\
Male & $15(60)$ \\
Pharmacy education & \\
Highest qualification & $25(100)$ \\
BPharm & $23(92)$ \\
Master's degree & $2(8)$ \\
Year in which BPharm was obtained & $25(100)$ \\
Before 2000 & $7(28)$ \\
2000 - 2010 & $18(72)$ \\
Current employment & \\
Province & $24(100)$ \\
Eastern Cape & $3(12)$ \\
Gauteng & $6(24)$ \\
KwaZulu-Natal & $0(0)$ \\
Limpopo & $1(4)$ \\
Mpumalanga & $2(16)$ \\
Western Cape & $11(44)$ \\
Location & $24(100)$ \\
Rural & $5(20)$ \\
Urban & $17(68)$ \\
Rural and urban & $2(16)$ \\
Health sector & $24(100)$ \\
Private & $12(50)$ \\
Public & $6(25)$ \\
Other & $6(25)$ \\
Level of care & $23(100)$ \\
Primary & $11(48)$ \\
Secondary & $5(22)$ \\
Other & \\
$*$ Other workplace health sectors included non-governmental organisations $(n=3)$, across public and \\
private institutions $(n=1)$ and as training consultants $(n=2)$. \\
Other practice descriptions included working acros the thee levels of care $(n=1)$, in training \\
$(n=2)$, policy research $(n=1)$, pharmaceutical industry $(n=2)$ and providing technical assistance to \\
the National Department of Health $(n=1)$. & \\
&
\end{tabular}

